\begin{tabular}{l|l} 
CANADIAN & THORACIC SOCIETY \\
SOCIÉTÉ & CANADIENNE DE THORACOLOGIE
\end{tabular}

\section{To all members}

$T_{\mathrm{b}}$ wo years ago, after much debate and discussion, the board of the Canadian Thoracic Society (CTS) decided to combine our annual meeting with the annual meeting of the American College of Chest Physicians (ACCP). There has been ongoing discussion as to whether this was the best course of action. Many members have raised the question of why we did not meet with the American Thoracic Society (ATS) or why we did not develop a standalone, made-in-Canada meeting.

\section{ACCP option}

- The board of the CTS spent a long time debating the best course of action for our society. After much discussion, it was felt that a collaboration with the ACCP was the best course to take to serve our membership.

- The executive body of the ACCP was very receptive to the idea of us developing a stand-alone CTS meeting within the broader ACCP annual meeting. The members of the executive body of the ACCP gave their time freely, they helped us with advertising and, finally, they gave our group space and an independent profile within their already well-established meeting.

- The ACCP has committed to a regular Canadian venue for their meeting every five years. This will bring significant revenue to the Canadian city chosen to host their annual meeting, with Montreal currently slated as the host city for 2005.

- Our Pulmonary Fellows are now being supported financially to attend the ACCP meeting, and we may find that there will be an increasing Canadian presence at the ACCP over time, as they complete their training.

- There are already several large pharmaceutical companies asking how they can support us in this new arena. This may give our Society some financial independence over the long term and allow us, in turn, to support new and innovative programs such as the Canadian Respiratory Proteomics Group or the Canadian Thoracic Society Clinical Trials Group. Without financial independence, we can offer these groups little other than our moral support.

- We are attempting to increase our membership to include all Canadian physicians practising in thoracic disorders. The ACCP meeting offers the opportunity to include new members with a primary clinical practice. This group has been relatively under-represented.
En français, voir page 163

- Our members are free to attend the CTS meeting only and are not obligated to stay for the remainder of the ACCP events. However, I believe that those who do not traditionally attend the ACCP meeting will be pleasantly surprised at its high educational quality.

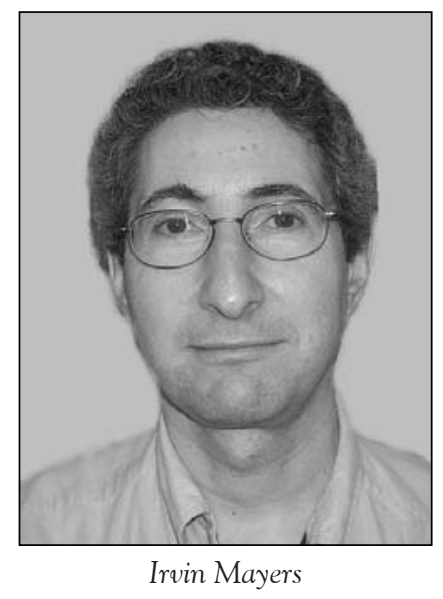

\section{ATS option}

- The annual ATS meeting has an advantage in that many Canadians already attend it. However, the meeting is already very full, and without the full willingness of the ATS to allocate specific times for CTS events on their program, we believed that we could not generate a unique Canadian event. This willingness was not present at the time that we needed to make decisions about our future meetings.

- The social aspects of Canadians meeting at the ATS events are already well established, and the CTS would have had to compete with these events.

- The ATS meeting is held only in the United States, with very rare exceptions. There would be little opportunity to have a combined meeting in Canada.

\section{Stand-alone option}

- We could model our meeting after other small Canadian groups such as Allergy and Immunology or the Canadian Immunology Society. In this manner, we could meet annually, and this meeting could develop into an excellent social event. As a community we are already inundated with low-profile meetings, and the board was concerned that we would create one more poorly attended meeting in Canada.

- This meeting would be very unlikely to generate significant support from pharmaceutical companies because it would be in competition with other events that are primarily driven by pharmaceutical companies. We did not think that it would generate sufficient excess revenue to give our Society any financial independence. 
- This meeting would be unlikely to bring in new members to create a broader base of support for our Society.

- Only about 25 members came to the annual CTS meeting when it was held in association with the Royal College of Physicians and Surgeons of Canada.

Our association with the ACCP does not mean that we will be unable to pursue an association with the ATS or with other organizations. We are negotiating a satellite symposium to be held in conjunction with the 2003 ATS meeting. We recognize that many of our members are now attending the annual European Respiratory Society meeting. With this in mind, we are actively exploring potential collaborations with the European Respiratory Society. We have even opened discussion in other countries with smaller groups, such as the Ecuadorian Thoracic Society.

We recognize that Canadians will continue to attend the ATS meeting to present their scientific achievements, and we actively encourage our members' presence at international meetings. We also recognize that the ATS meeting serves an important social function for many of our members. However, as the Canadian presence at the CTS/ACCP meeting grows, the social aspects of the meeting will also grow. CTS members in increased numbers may also elect to present their scientific achievements at the ACCP meeting. It is important to understand that the ACCP is willing to collaborate with us in developing a new approach to holding our annual meeting. We can maintain a uniquely Canadian identity and presence in a truly North American venue. Without a commitment from our membership to support the CTS meeting, we will be left as an orphan society with minimal financial resources, dependent on the good will of the Canadian Lung Association or on the good will of a pharmaceutical company to hold an annual general meeting. As CTS members, your support and commitment for this new endeavour is essential for any hope of success. The Canadian speakers have already been chosen for our upcoming meeting. We encourage all of you to come and show your support for the Society that represents you on the national and, now, on an international stage.

The next CTS annual general meeting will be held in San Diego, California on November 3, 2002.

Irvin Mayers MD FRCPC President, Canadian Thoracic Society 


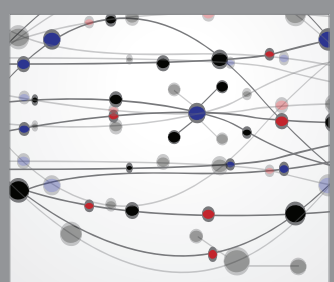

The Scientific World Journal
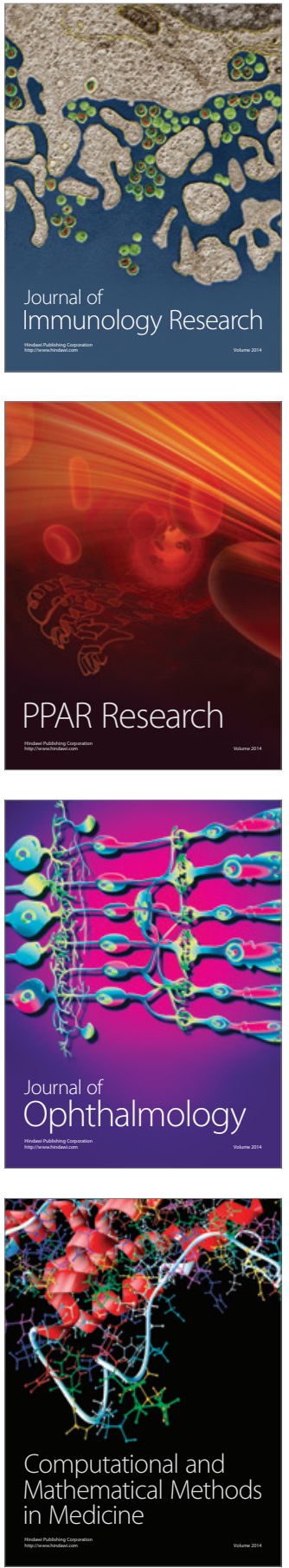

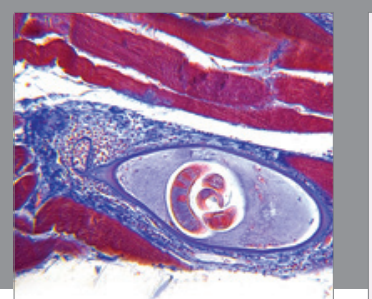

Gastroenterology Research and Practice

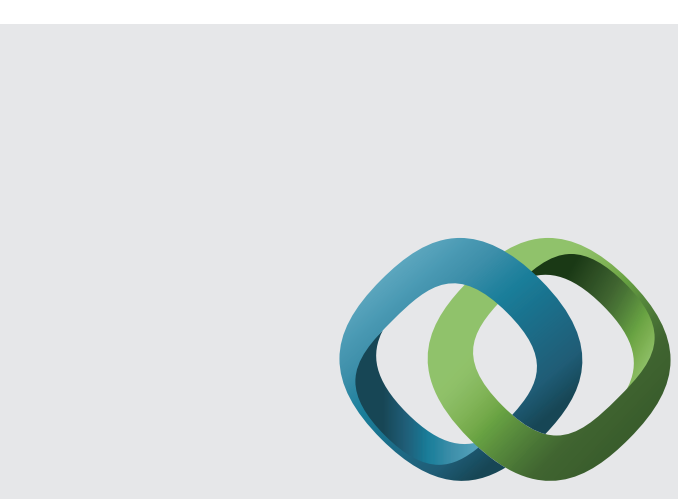

\section{Hindawi}

Submit your manuscripts at

http://www.hindawi.com
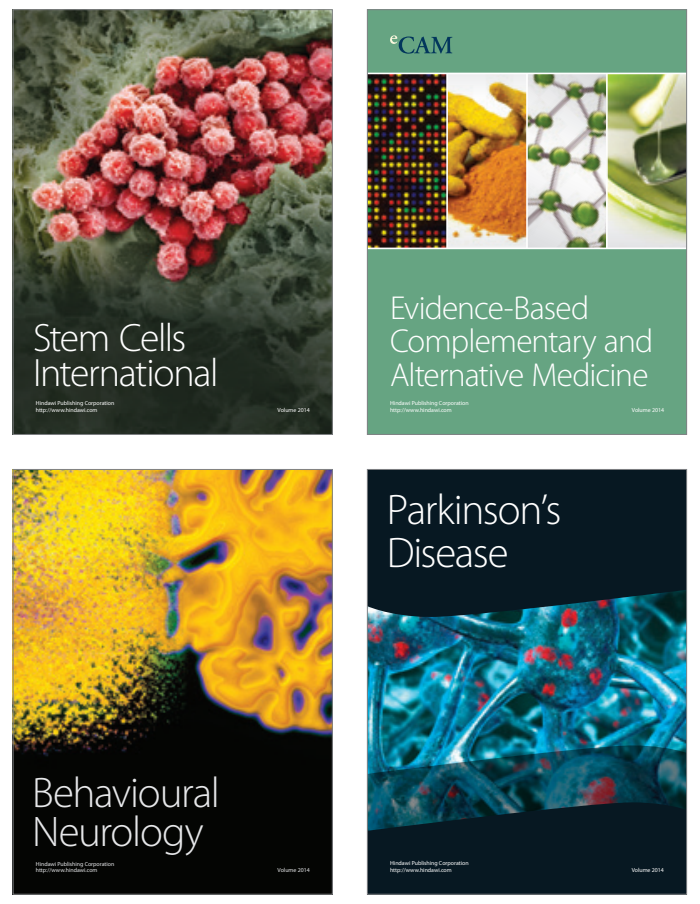
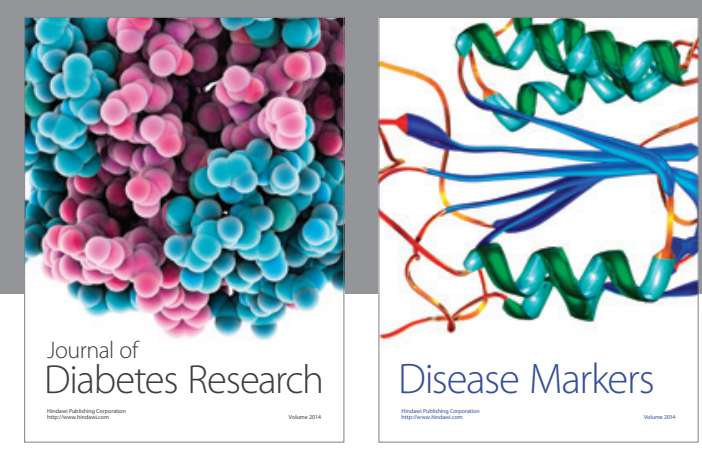

Disease Markers
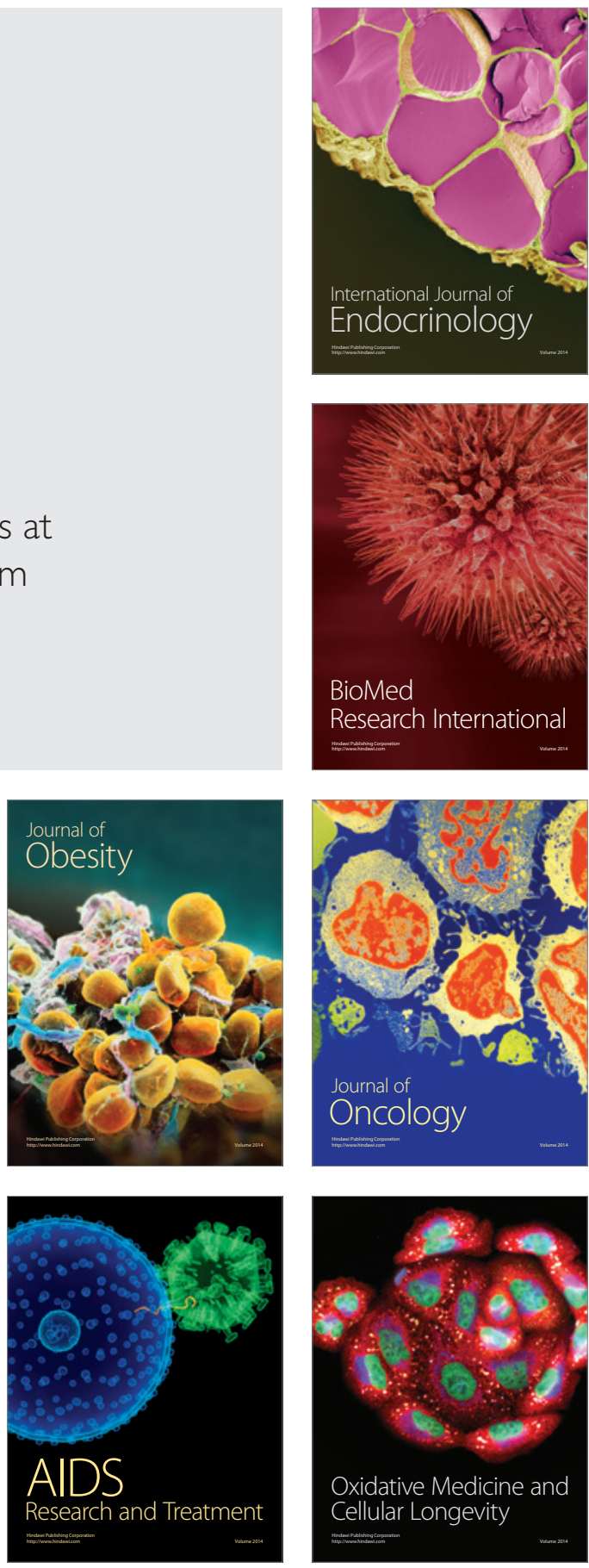